\title{
Inhibition of osteoblast differentiation by ritonavir
}

\author{
YOSHITAKA WAKABAYASHI $^{1}$, YUSUKE YOSHINO ${ }^{2}$, KAZUNORI SEO $^{2}$, \\ ICHIRO KOGA ${ }^{2}$, TAKATOSHI KITAZAWA ${ }^{2}$ and YASUO OTA ${ }^{2}$ \\ ${ }^{1}$ Department of Infectious Diseases, The University of Tokyo Hospital, Tokyo 113-8655; \\ ${ }^{2}$ Department of Internal Medicine, Teikyo University, Tokyo 173-8606, Japan
}

Received March 30, 2018; Accepted September 26, 2018

DOI: $10.3892 /$ br.2018.1154

\begin{abstract}
Osteoporosis is one of the chronic complications seen in human immunodeficiency virus (HIV)-infected patients, and affects patients at high prevalence. The causes of osteoporosis in HIV-infected patients are multiple, and include chronic HIV infection, living habits such as smoking and alcohol consumption, and antiretroviral drug use. Among antiretroviral drugs, protease inhibitors have been reported to be associated with osteoporosis. However, it remains to be determined how anti-HIV drugs affect osteoblast differentiation. In the current study, MC3T3-E1 cells, a mouse osteoblastic cell line, were cultured in osteoblast differentiation medium with or without different protease inhibitors (ritonavir, lopinavir, darunavir or atazanavir), and alkaline phosphatase (ALP) activity and the expression of Runt-related transcription factor 2 (Runx2) were analyzed. The ALP activity in MC3T3-E1 cells cultured with ritonavir was significantly reduced compared with that in cells in only osteoblast inducer reagent, indicating that ritonavir inhibited osteoblast differentiation. Meanwhile, ALP activity was not reduced in cells cultured with any of the other inhibitors. In addition, ritonavir inhibited the expression of Runx2, a key regulator of osteoblast differentiation, in the early period of osteoblast differentiation. To the best of our knowledge, this is the first study to demonstrate that ritonavir inhibits osteoblast differentiation in vitro. The present findings may explain the mechanism of osteopenia induced by combination antiretroviral therapy involving protease inhibitors.
\end{abstract}

\section{Introduction}

The progress of combination antiretroviral therapy (cART) has led to increased life expectancy of patients infected with human immunodeficiency virus (HIV) (1). However, as life expectancy has increased, chronic complications have become key chal-

Correspondence to: Dr Yusuke Yoshino, Department of Internal Medicine, Teikyo University, 2-11-1 Kaga, Itabashi-ku, Tokyo 173-8606, Japan

E-mail: yyoshino@med.teikyo-u.ac.jp

Key words: ritonavir, protease inhibitor, human immunodeficiency virus, antiretroviral therapy, osteoporosis, osteoblast differentiation lenges (2). Osteoporosis is among the chronic complications seen in HIV-infected patients; the prevalence of osteoporosis is reportedly three times higher among HIV-infected patients than non-HIV-infected patients (3). The reported prevalence rate of osteopenia in HIV-infected cohorts ranges from 22 to $71 \%$, and that of osteoporosis from 3 to $33 \%$ (4). The causes of osteoporosis in HIV-infected patients are multiple, and include chronic HIV infection, living habits such as smoking and alcohol consumption, and antiretroviral drug use (5). Among antiretroviral drugs, protease inhibitors have been reported to be associated with osteoporosis, and antiretroviral regimens containing protease inhibitors can accelerate osteopenia and osteoporosis (6).

Osteoporosis is caused by an imbalance of bone resorption and formation (7). Osteoclasts have a role in bone formation, and osteoblasts that are derived from mesenchymal stem cells are responsible for bone formation (8). Osteoblast differentiation is regulated by transcription factors including Runt-related transcription factor 2 (Runx2) (9). Runx2 is a positive regulator of genes associated with bone matrix proteins including collagen type I $\alpha 1 / 2$ chain (9), and triggers the expression of major bone matrix genes during the early stages of osteoblast differentiation (9). As such, Runx2 is considered to serve a central role in skeletal development and be associated with osteoporosis (9). However, it remains to be determined specifically how anti-HIV drugs affect osteoblast differentiation. Thus, in the present study, the influence of anti-HIV drugs on osteoblast differentiation was examined in vitro.

\section{Materials and methods}

Cell line and culture. The clonal mouse osteoblastic cell line, MC3T3-E1 subclone 14, was purchased from American Type Culture Collection (Manassas, VA, USA). The MC3T3-E1 cells were cultured at $37^{\circ} \mathrm{C}$ in $5 \% \mathrm{CO}_{2}$ in Dulbecco's modified Eagle's medium (DMEM; Sigma-Aldrich; Merck KGaA, Darmstadt, Germany) with $10 \%$ fetal bovine serum (Hyclone; GE Healthcare Life Science, Logan, UT, USA), 100 IU/ml penicillin and $100 \mu \mathrm{g} / \mathrm{ml}$ streptomycin. To induce osteoblast differentiation, MC3T3-E1 cells were cultured at $37^{\circ} \mathrm{C}$ in $5 \% \mathrm{CO}_{2}$ in DMEM with osteoblast inducer reagent containing $1 \%$ L-ascorbic acid, $2 \% \beta$-glycerophosphate and $0.2 \%$ hydrocortisone (Takara Bio, Inc., Otsu, Japan). The medium was changed every other day. 
Anti-HIV drugs. The HIV protease inhibitors ritonavir, darunavir, atazanavir and lopinavir were purchased from Toronto Research Chemicals, Inc. (Toronto, ON, Canada). These drugs were prepared as stock solutions in methanol. All prepared anti-HIV drugs were mixed with osteoblast differentiation medium to adjust to the maximum serum concentration (Cmax) that these drugs achieve when they are administered at treatment doses in adult HIV patients. Cmax values of protease inhibitors were based on those on the University of Liverpool website, www.hiv-druginteraction.org. The Cmax values were: Ritonavir, $11.20 \mu \mathrm{g} / \mathrm{ml}$; lopinavir, $9.60 \mu \mathrm{g} / \mathrm{ml}$; darunavir, $6.50 \mu \mathrm{g} / \mathrm{ml}$; and atazanavir $3.15 \mu \mathrm{g} / \mathrm{ml}$.

Alkaline phosphatase (ALP) activity. MC3T3-E1 cells were seeded at a density of $1 \times 10^{4}$ cells/well in a 96-well microplate in normal culture medium. To induce differentiation, the medium was replaced by DMEM with osteoblast inducer reagent after 1 day in the presence or absence of each protease inhibitor, respectively. The cells were incubated for 7 and 9 days in four types of medium: i) DMEM; ii) DMEM with osteoblast inducer reagent; iii) DMEM with osteoblast inducer reagent and an anti-HIV drug; and iv) DMEM with vehicle (methanol). For subsequent treatments with ritonavir, MC3T3-E1 cells were treated with various concentrations $(0.1$, $0.5,1.0,5.0$ and $10.0 \mu \mathrm{g} / \mathrm{ml}$ ritonavir) and for various durations $(10.0 \mu \mathrm{g} / \mathrm{ml}$ ritonavir for 9,11 and 14 days). All cells were cultured at $37^{\circ} \mathrm{C}$ in a $5 \% \mathrm{CO}_{2}$ atmosphere. ALP activity was evaluated using a TRACP \& ALP double-staining kit (Takara Bio, Inc.) according to the manufacturer's protocol. Briefly, the plates were incubated with kit reagents at $37^{\circ} \mathrm{C}$ for $15 \mathrm{~min}$, absorbance was measured at $405 \mathrm{~nm}$, and ALP activity was calculated from a standard value (bone ALP; Takara Bio, Inc.). The total protein concentration of each cell was determined by a DC ${ }^{\mathrm{TM}}$ Protein Assay (Bio-Rad Laboratories, Inc., Hercules, CA, USA), and the activity data were normalized to the total protein concentration.

Alizarin Red staining. MC3T3-E1 cells were seeded at a density of $4 \times 10^{4}$ cells/well in a 24 -well plate. The cells were incubated with $10.0 \mu \mathrm{g} / \mathrm{ml}$ ritonavir or control mediums as above. Mineralization of MC3T3-E1 cells was confirmed by using an Alizarin Red S staining kit (Cosmo Bio, Co., Ltd., Tokyo, Japan) after 7, 14, 21 and 28 days of culture. Then, cells were washed three times with phosphate-buffered saline, with $500 \mu 1$ of $100 \%$ methanol added to each well, and incubated at $4^{\circ} \mathrm{C}$ for $20 \mathrm{~min}$. Alizarin Red solution was added to each well and incubated at room temperature for $5 \mathrm{~min}$. Each well was then washed again three times and directly observed.

Total RNA extraction and cDNA synthesis. MC3T3-E1 cells seeded at $1 \times 10^{5}$ cells/well in a 12 -well plate were incubated with $10.0 \mu \mathrm{g} / \mathrm{ml}$ ritonavir or control mediums as above for 3 , 5 and 7 days. Total RNA was extracted from the MC3T3-E1 cells by adding $350 \mu \mathrm{l}$ Tripure (Roche, Basel, Switzerland) to each well. RNA was isolated according to the manufacturer's instructions. Total RNA was reverse-transcribed into cDNA by using ReverTra Ace ${ }^{\circledR}$ qPCR RT Master Mix (Toyobo Life Science, Osaka, Japan) according to the manufacturer's instructions.
Quantitative polymerase chain reaction $(q P C R)$. Runx2 gene expression in MC3T3-E1 cells was examined by qPCR. $\beta$-actin was used as an internal control gene. The qPCR was performed with a Roche LightCycler 480 system using a LightCycler 480 Probe Master kit (Roche Diagnostics, Basel, Switzerland). Reactions were performed in a final total volume of $20 \mu \mathrm{l}$ containing $1 \mathrm{x}$ LightCycler 480 Probe Master mix, $0.1 \mu \mathrm{M}$ of each forward and reverse primer, $3.8 \mu \mathrm{l}$ distilled $\mathrm{H}_{2} \mathrm{O}$ and $5 \mu \mathrm{l}$ of the cDNA template. Specific primers for mouse Runx 2 and $\beta$-actin were designed using the Universal ProbeLibrary (Roche Diagnostics). The primers used in the current study were as follows: For Runx2, forward, 5'-cgtgtcagcaaagcttctttt-3' and reverse, 5'-ggctcacgtcgctcatct-3'; and for $\beta$-actin, forward, 5'-tgacaggatgcagaaggaga-3' and reverse, $5^{\prime}$-cgctcaggaggagcaatg-3'. The amplification conditions were as follows: Denaturation at $95^{\circ} \mathrm{C}$ for $5 \mathrm{~min}, 45$ cycles of amplification $\left(95^{\circ} \mathrm{C}\right.$ for $10 \mathrm{sec}, 60^{\circ} \mathrm{C}$ for $30 \mathrm{sec}$ and $72^{\circ} \mathrm{C}$ for $1 \mathrm{sec}$ ), and cooling at $50^{\circ} \mathrm{C}$ for $10 \mathrm{sec}$. Relative quantification of target gene expression was determined using the E-Method (Efficiency Method) from the LightCycler 480 software (10).

Lactate dehydrogenase $(\mathrm{LDH})$ activity assay. $\mathrm{LDH}$ activity was measured to determine MC3T3-E1 cell viability following treatment with ritonavir. MC3T3-E1 cells were plated in 12 -well plates $\left(1 \times 10^{5}\right.$ cells/well) and incubated in DMEM with osteoblast inducer reagent in the presence or absence of ritonavir $(10 \mu \mathrm{g} / \mathrm{ml})$. On day 8 , culture medium was replenished and cells were cultured again for $24 \mathrm{~h}$. Cell medium and lysate extracted with radioimmunoprecipitation assay buffer (Wako Pure Chemical Industries, Ltd., Osaka, Japan) were collected on day 9, and cell viability was evaluated using Cytotoxicity detection KitPLUS (Roche Diagnostics) according to the manufacturer's protocol. Cells in DMEM only were defined as a control. The absorbance was measured at $490 \mathrm{~nm}$, and cell viability was calculated using the following formula: Cell viability $(\%)=\{1-[$ (absorbance of medium - absorbance of control medium)/(absorbance of lysate - absorbance of control lysate)]\} x100.

Statistical analysis. Significant differences among samples were determined by one-way analysis of variance with post hoc Tukey's honest significant difference test, with $\mathrm{P}<0.05$ considered to indicate statistical significance. At least three samples were tested in three independent experiments. All results are presented as means \pm standard error of the mean. The data analysis was performed using JMP software version 12.2 (SAS Institute, Inc., Cary, NC, USA).

\section{Results}

Osteoblast differentiation is inhibited by ritonavir. As documented, osteoblasts are differentiated by a medium that contains L-ascorbic acid, $\beta$-glycerophosphate and steroid (11). Since ALP activity is enhanced during osteoblast differentiation in vitro, ALP may be used as an osteogenic differentiation marker (12). First, the present study observed that ALP activity was enhanced in MC3T3-E1 cells at 7 days after the addition of DMEM with osteoblast inducer reagent compared with in cells cultured in DMEM only $(\mathrm{P}<0.05$; data not shown). Subsequently, the effect of protease inhibitors on 

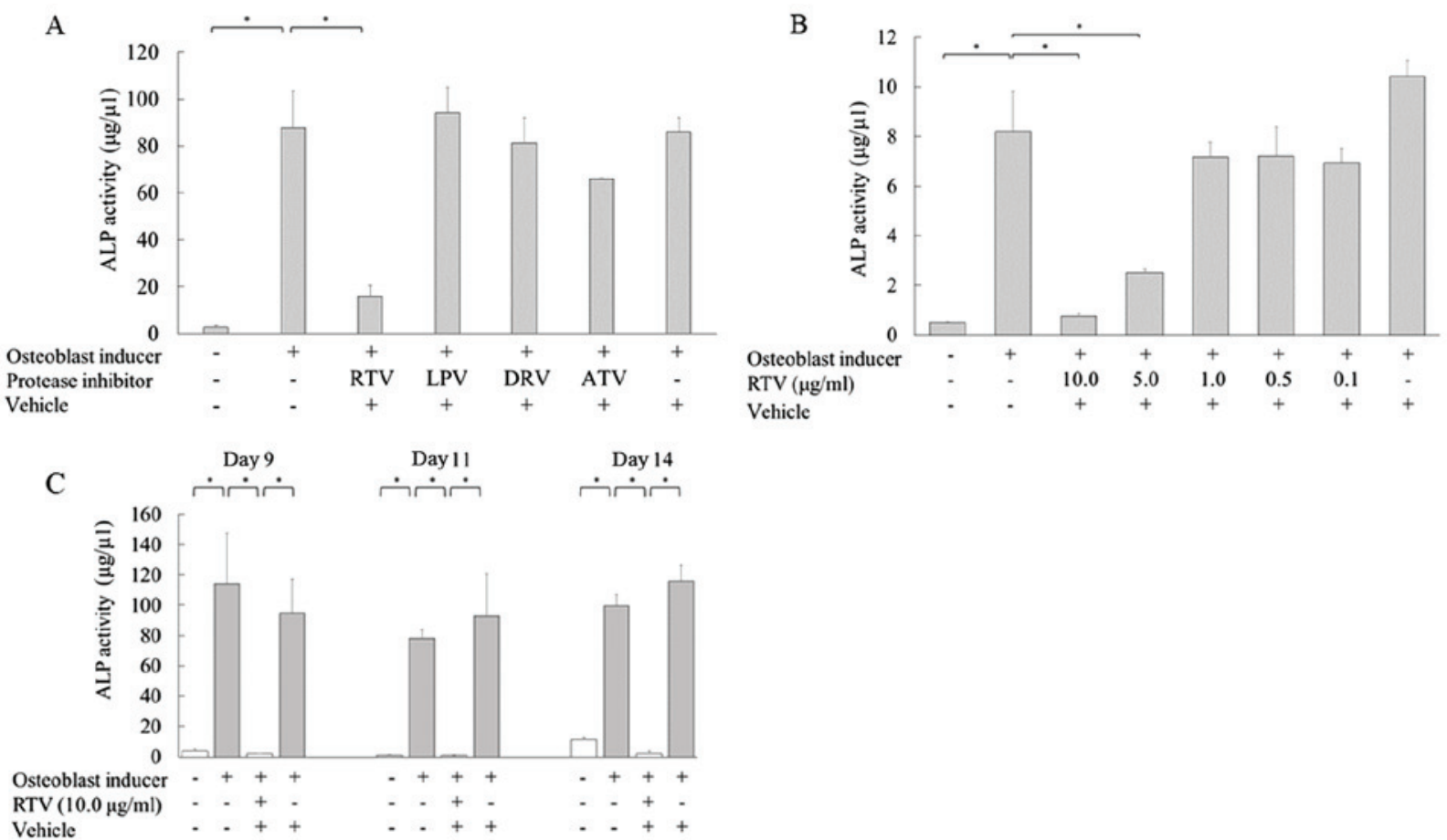

Figure 1. Ritonavir reduces the ALP activity in MC3T3-E1 cells. (A) MC3T3-E1 cells were cultured in osteoblast differentiation medium with or without Cmax doses of protease inhibitors for 9 days, and ALP activity was analyzed. (B) Cells were cultured in osteoblast differentiation medium with various concentrations of ritonavir $(0,0.1,0.5,1.0,5.0$ and $10.0 \mu \mathrm{g} / \mathrm{ml})$ for 9 days, and ALP activity was measured quantitatively. (C) Cells were cultured in osteoblast differentiation medium with or without $10.0 \mu \mathrm{g} / \mathrm{ml}$ ritonavir for 9,11 and 14 days, and ALP activity was analyzed. All data are presented as means \pm standard deviation. " $\mathrm{P}<0.05$. ALP, alkaline phosphatase; Cmax, maximum serum concentration; RTV, ritonavir; LPV, lopinavir; DRV, darunavir; ATV, atazanavir.

osteoblast differentiation was examined. MC3T3-E1 cells were cultured in osteogenic differentiation medium in the presence or absence of the protease inhibitors ritonavir, lopinavir, darunavir and atazanavir $3.15 \mu \mathrm{g} / \mathrm{ml}$ at their Cmax for 9 days, and then ALP activity was examined. The ALP activity of MC3T3-E1 cells cultured with ritonavir was significantly reduced compared with that of the control cells in osteoblast induction medium alone $(\mathrm{P}<0.05)$. However, ALP activity was not reduced in cells cultured with the other anti-HIV drugs (Fig. 1A). These results indicated that the protease inhibitor ritonavir inhibited osteoblast differentiation.

Next, the relationship between ritonavir concentration and osteoblast differentiation was examined. MC3T3-E1 cells were treated with various concentrations of ritonavir $(0.1,0.5,1.0$, 5.0 and $10.0 \mu \mathrm{g} / \mathrm{ml})$. ALP activity was significantly reduced in MC3T3-E1 cells cultured with 5.0 or $10.0 \mu \mathrm{g} / \mathrm{ml}$ ritonavir compared with the controls in osteoblast induction medium alone $(\mathrm{P}<0.05)$; however, lower concentrations of ritonavir did not inhibit ALP activity (Fig. 1B).

The time course of ALP activity in MC3T3-E1 cells cultured with ritonavir was also examined. MC3T3-E1 cells were cultured in osteogenic differentiation medium with or without $10.0 \mu \mathrm{g} / \mathrm{ml}$ ritonavir for 9,11 and 14 days. ALP activity was significantly reduced following ritonavir treatment at each time point $(\mathrm{P}<0.05$; Fig. $1 \mathrm{C})$.

Effect of ritonavir on the expression of Runx2 in MC3T3-E1 cells. RUNX2 is the key gene responsible for the differentiation of human mesenchymal cells into osteoblasts; it upregulates bone matrix proteins including ALP in the early phase of osteoblast differentiation (13). MC3T3-1 cells were cultured in osteogenic differentiation medium with or without $10.0 \mu \mathrm{g} / \mathrm{ml}$ ritonavir for 3, 5 and 7 days, and the mRNA expression of Runx 2 was measured by reverse transcription-qPCR. On days 3 and 5, the mRNA levels of Runx 2 were significantly reduced in differentiating cells cultured with ritonavir compared with in the differentiating controls $(\mathrm{P}<0.05)$; however, no significant differences were observed on day 7 (Fig. 2). These results indicated that ritonavir inhibited expression of Runx 2 in the early phase of osteoblast differentiation.

Osteoblast mineralization is inhibited by ritonavir. In the process of bone formation, osteoblasts need to differentiate and mineralize. Thus, whether ritonavir inhibited osteoblast mineralization was examined. MC3T3-E1 cells were cultured in DMEM with osteoblast inducer reagent with or without $10 \mu \mathrm{g} / \mathrm{ml}$ ritonavir for 7, 14, 21 and 28 days. Then, cells were stained with Alizarin Red S to assess mineralization. At 7 and 14 days, cells treated with DMEM or with osteoblast induction medium, with or without ritonavir, exhibited no positive staining indicative of mineralization. At 21 and 28 days, cells treated with osteoblast induction medium with or without vehicle exhibited increasing mineralization, while those treated with DMEM only or osteoblast induction medium with ritonavir were not (Fig. 3). These results indicated that ritonavir suppressed or delayed osteoblast mineralization.

Cell viability of MC3T3-E1 cells treated with ritonavir. The cytotoxicity of ritonavir was assessed via measuring LDH activity. MC3T3-E1 cells were cultured in osteogenic differentiation medium with or without $10.0 \mu \mathrm{g} / \mathrm{ml}$ ritonavir for 9 days, and the levels of LDH activity were measured. 


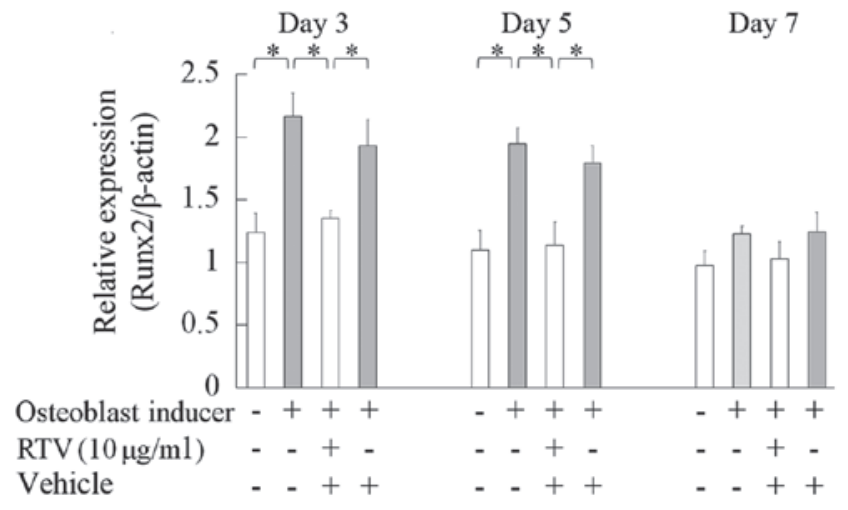

Figure 2. Ritonavir reduces the expression of Runx2 mRNA in MC3T3-E1 cells. Cells were cultured in osteoblast differentiation medium with or without $10.0 \mu \mathrm{g} / \mathrm{ml}$ ritonavir for 3, 5 and 7 days. Runx 2 mRNA expression was evaluated by reverse transcription-quantitative polymerase chain reaction. The data are presented as means \pm standard deviation. ${ }^{*} \mathrm{P}<0.05$ Runx2, runt-related transcription factor 2; RTV, ritonavir.

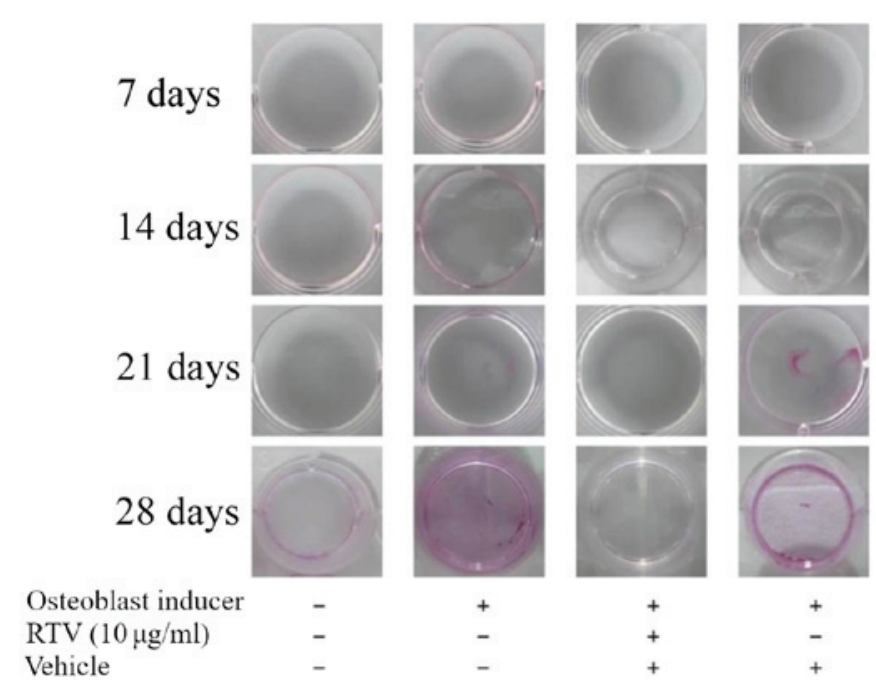

Figure 3. Ritonavir suppresses osteoblast mineralization in MC3T3-E1 cells. Cells were cultured in osteoblast differentiation medium with or without $10.0 \mu \mathrm{g} / \mathrm{ml}$ ritonavir for up to 28 days. Alizarin red S staining was performed. RTV, ritonavir

There were no statistically significant differences among the groups (Fig. 4). These results showed that ritonavir did not exert cytotoxic effects in MC3T3-E1 cells.

\section{Discussion}

Osteoporosis is one of the complications seen in patients with HIV. HIV itself suppresses osteogenesis (14). Several in vivo studies have reported that osteopenia and osteoporosis are common among patients treated with antiretroviral drugs (15-18). Bedimo et al (15) reported that cumulative exposure to tenofovir and protease inhibitors, particularly lopinavir/ritonavir, was an independent predictor of increased risk of osteoporotic fracture in HIV patients on cART. Further, it was shown in the Data collection on Adverse events of anti-HIV Drugs study that protease inhibitor use was one of the risk factors for osteoporosis $(16,17)$. Duvivier et al (18) reported that decreased lumbar spine bone mineral density

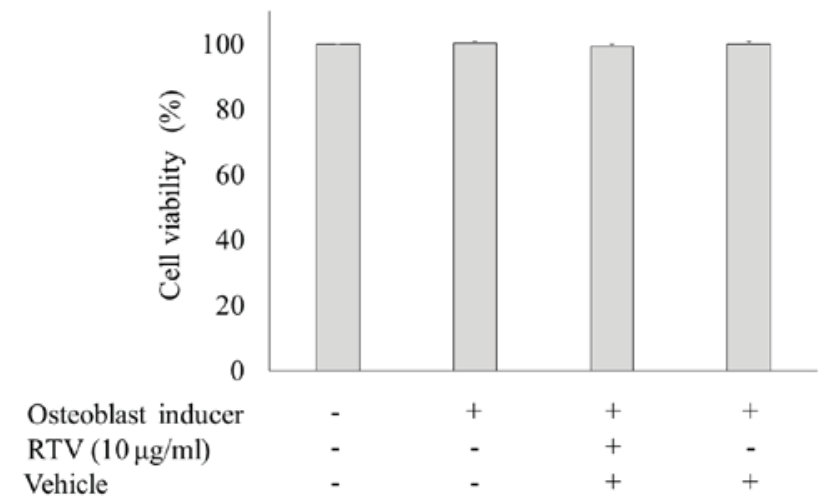

Figure 4. Ritonavir did not affect MC3T3-E1 cell viability. Cells were cultured in osteoblast differentiation medium with or without $10.0 \mu \mathrm{g} / \mathrm{ml}$ ritonavir for 9 days, and the levels of LDH activity were measured. The data are presented as means \pm standard deviation. $\mathrm{LDH}$, lactate dehydrogenase; RTV, ritonavir.

was more pronounced in patients receiving protease inhibitors (indinavir/ritonavir or lopinavir/ritonavir) compared with other antiretroviral drugs. By contrast, a cross-sectional study identified decreased bone density in HIV-positive patients irrespective of treatment with or without protease inhibitors (19). Thus, the association between osteoporosis and protease inhibitors in vivo is yet to be confirmed.

The MC3T3-E1 cell line is a pre-osteoblast line derived from mouse calvaria (20). It is established to exhibit a time-dependent and sequential expression of osteoblast characteristics analogous to in vivo bone formation, and is used as a bone differentiation and mineralization model in vitro (21). In the present study, ritonavir was indicated to affect the pathway of osteoblast differentiation and the time course of differentiation. There are a number of in vitro reports describing the relationship between certain antiretroviral drugs and osteoblast differentiation $(21,22)$. Jain and Lenhard reported that two protease inhibitors, lopinavir and nelfinavir, decreased osteoblast ALP activity and gene expression in human mesenchymal stem cells (21). Another report demonstrated that ALP activity decreased significantly in human osteoblast cultures following exposure to nelfinavir and indinavir (22). Santiago et al has previously reported ritonavir may facilitate osteoclast differentiation (23); however, other findings have suggested that ritonavir could inhibit osteoclast formation and function (24). Thus, the exact effect of RTV on osteoblast cells remained unknown.

Ritonavir was originally used for its antiviral action, but is now used as a booster of other protease inhibitors. The therapeutic adult dose of ritonavir is $600 \mathrm{mg}$ twice a day. When $600 \mathrm{mg}$ ritonavir is taken twice a day, the mean maximum and minimum serum concentrations (Cmax and $\mathrm{Cmin}$ ) of ritonavir have been determined as $11.2 \pm 3.6$ and $3.7 \pm 2.6 \mu \mathrm{g} / \mathrm{ml}$, respectively (25). In the present study, osteoblast differentiation was inhibited by 5.0 and $10.0 \mu \mathrm{g} / \mathrm{ml}$ ritonavir. These results indicated the possibility that administration of therapeutic doses of ritonavir may inhibit osteoblast differentiation in vivo. However, as a booster, ritonavir is used at a dose of 100 to $200 \mathrm{mg}$ a day, and the expected ritonavir Cmax is $\sim 1.5 \mu \mathrm{g} / \mathrm{ml}$, and therefore osteoblast differentiation appears unlikely to be inhibited in vivo. However, to our knowledge 
there are no reports of a pharmacokinetic analysis of ritonavir in bone. Thus, osteoblast differentiation may be suppressed in bone when the booster dose of ritonavir is administered.

In the present study, ritonavir suppressed the expression of Runx 2 mRNA. To the best of our knowledge, this is the first study to report a suppressive effect of ritonavir on the expression of Runx2, and that ritonavir may affect osteoblast differentiation and mineralization in MC3T3-E1 cells. There are numerous pathways associated with osteoblast differentiation including the bone morphogenetic protein BMP and parathyroid hormone pathways (26). Runx2 is an essential transcription factor required for osteogenesis; Runx2-knockout mice exhibit a complete absence of mature osteoblasts and ossification (26). In particular, Runx 2 is a key regulator of osteoblast differentiation and regulates the expression of several osteoblastic genes, including collagen 1, osteopontin, osteocalcin and bone sialoprotein, to induce differentiation (13). In primary osteoblast cells isolated from the calvariae of rats, study has found ALP activity to be significantly decreased by Runx2 small interfering RNA treatment when cells were treated with osteoblast differentiation medium that included ascorbic acid and $\beta$-glycerophosphate (27), indicating that Runx 2 expression is upstream of ALP. In the present study, the expression of Runx 2 mRNA was suppressed on days 3 and 5, but not on day 7 of treatment with ritonavir in osteoblast differentiation medium. Prior to day 7, the ALP activities of cells with or without differentiation medium did not change (not shown). But ALP activities were suppressed on day 9 or later of treatment with ritonavir in osteoblast differentiation medium. These results collectively indicate that ritonavir suppressed Runx 2 directly or other regulators of osteoblast differentiation upstream of Runx2, and, as a result, ALP activity was suppressed.

The present results also suggested inhibition of osteoblast mineralization by ritonavir. However, bone formation takes 3 to 4 months (28), and cells in the current study were cultured for only 28 days (4 weeks). Thus, the possibility that ritonavir simply delayed osteoblast mineralization cannot be excluded.

In conclusion, the present study is seemingly the first to demonstrate that ritonavir may inhibit osteoblast differentiation in vitro. Expression of Runx 2 was suppressed by ritonavir in MC3T3-E1 cells. This may explain the mechanism of osteopenia induced by cART involving protease inhibitors.

\section{Acknowledgements}

Not applicable.

\section{Funding}

No funding was received.

\section{Availability of data and materials}

The datasets used and/or analyzed during the current study are available from the corresponding author on reasonable request.

\section{Authors' contributions}

YW, YY, KS, IK, TK and YO designed the study. YW processed the experimental data, performed the analysis, drafted the manuscript and produced the figures. All authors discussed the results and contributed to the final manuscript.

\section{Ethics approval and consent to participate}

Not applicable.

\section{Patient consent for publication}

Not applicable.

\section{Competing interests}

The authors declare that they have no competing interests.

\section{References}

1. Lohse N, Hansen AB, Gerstoft J and Obel N: Improved survival in HIV-infected persons: Consequences and perspectives. J Antimicrob Chemother 60: 461-463, 2007.

2. Maartens G, Celum C and Lewin SR: HIV infection: Epidemiology, pathogenesis, treatment, and prevention. Lancet 384: 258-271, 2014.

3. Brown TT and Qaqish RB: Antiretroviral therapy and the prevalence of osteopenia and osteoporosis: A meta-analytic review. AIDS 20: 2165-2174, 2006.

4. Del Carpio-Cano FE, Dela Cadena RA and Sawaya BE: HIV and bone disease: A perspective of the role of microRNAs in bone biology upon HIV infection. J Osteoporos 2013: 571418, 2013.

5. McComsey GA, Tebas P, Shane E, Yin MT, Overton ET, Huang JS, Aldrovandi GM, Cardoso SW, Santana JL and Brown TT: Bone disease in HIV infection: A practical review and recommendations for HIV care providers. Clin Infect Dis 51: 937-946, 2010.

6. Tebas P, Powderly WG, Claxton S, Marin D, Tantisiriwat W, Teitelbaum SL and Yarasheski KE: Accelerated bone mineral loss in HIV-infected patients receiving potent antiretroviral therapy. AIDS 14: F63-F67, 2000.

7. Kanis JA: Assessment of fracture risk and its application to screening for postmenopausal osteoporosis: Synopsis of a WHO report. WHO Study Group. Osteoporos Int 4: 368-381, 1994.

8. Endo I and Mastumoto T: Bone and stem cells: Regulatory mechanism of mesenchymal stem cell differentiation to osteoblasts. Clin Calcium 24: 555-564, 2014 (In Japanese).

9. Komori T: Regulation of bone development and maintenance by Runx2. Front Biosci 13: 898-903, 2008.

10. Tellmann G: The E-Method: A highly accurate technique for gene-expression analysis. Nat Methods 3: i-ii, 2006.

11. Jaiswal N, Haynesworth SE, Caplan AI and Bruder SP: Osteogenic differentiation of purified, culture-expanded human mesenchymal stem cells in vitro. J Cell Biochem 64: 295-312, 1997.

12. Pittenger MF, Mackay AM, Beck SC, Jaiswal RK, Douglas R, Mosca JD, Moorman MA, Simonetti DW, Craig S and Marshak DR: Multilineage potential of adult human mesenchymal stem cells. Science 284: 143-147, 1999.

13. Xiao ZS, Liu SG, Hinson TK and Quarles LD: Characterization of the upstream mouse Cbfa1/Runx2 promoter. J Cell Biochem 82: 647-659, 2001

14. Cotter EJ, Malizia AP, Chew N, Powderly WG and Doran PP: HIV proteins regulate bone marker secretion and transcription factor activity in cultured human osteoblasts with consequent potential implications for osteoblast function and development. AIDS Res Hum Retroviruses 23: 1521-1530, 2007.

15. Bedimo R, Maalouf NM, Zhang S, Drechsler H and Tebas P: Osteoporotic fracture risk associated with cumulative exposure to tenofovir and other antiretroviral agents. AIDS 26: 825-831, 2012.

16. Friis-Møller N, Reiss P, Sabin CA, Weber R, Monforte A, El-Sadr W, Thiébaut R, De Wit S, Kirk O, Fontas E, et al: DAD Study Group: Class of antiretroviral drugs and the risk of myocardial infarction. N Engl J Med 356: 1723-1735, 2007.

17. Flint OP, Noor MA, Hruz PW, Hylemon PB, Yarasheski K, Kotler DP, Parker RA and Bellamine A: The role of protease inhibitors in the pathogenesis of HIV-associated lipodystrophy: Cellular mechanisms and clinical implications. Toxicol Pathol 37: 65-77, 2009. 
18. Duvivier C, Kolta S, Assoumou L, Ghosn J, Rozenberg S, Murphy RL, Katlama C and Costagliola D; ANRS 121 Hippocampe study group: Greater decrease in bone mineral density with protease inhibitor regimens compared with nonnucleoside reverse transcriptase inhibitor regimens in HIV-1 infected naive patients. AIDS 23: 817-824, 2009.

19. Amiel C, Ostertag A, Slama L, Baudoin C, N'Guyen T, Lajeunie E, Neit-Ngeilh L, Rozenbaum W and De Vernejoul MC: BMD is reduced in HIV-infected men irrespective of treatment. J Bone Miner Res 19: 402-409, 2004.

20. Kodama H, Amagai Y, Sudo H, Kasai S and Yamamoto S: Establishment of a clonal osteogenic cell linefrom newborn mouse calvaria. Jap J Oral Biol 23: 899-901, 1981.

21. Jain RG and Lenhard JM: Select HIV protease inhibitors alter bone and fat metabolism ex vivo. J Biol Chem 277: 19247-19250, 2002.

22. Malizia AP, Cotter E, Chew N, Powderly WG and Doran PP: HIV protease inhibitors selectively induce gene expression alterations associated with reduced calcium deposition in primary human osteoblasts. AIDS Res Hum Retroviruses 23: 243-250, 2007.

23. Santiago F, Oguma J, Brown AM and Laurence J: Noncanonical Wnt signaling promotes osteoclast differentiation and is facilitated by the human immunodeficiency virus protease inhibitor ritonavir. Biochem Biophys Res Commun 417: 223-230, 2012.
24. Wang MW, Wei S, Faccio R, Takeshita S, Tebas P, Powderly WG, Teitelbaum SL and Ross FP: The HIV protease inhibitor ritonavir blocks osteoclastogenesis and function by impairing RANKL-induced signaling. J Clin Invest 114: 206-213, 2004.

25. Ltd AL: Norvir ${ }^{\circledR}$ Tablets Summary of Product Characteristics. 2010.

26. Komori T, Yagi H, Nomura S, Yamaguchi A, Sasaki K, Deguchi K, Shimizu Y, Bronson RT, Gao YH, Inada M, et al: Targeted disruption of Cbfa1 results in a complete lack of bone formation owing to maturational arrest of osteoblasts. Cell 89: 755-764, 1997.

27. Lin L, Shen Q, Leng H, Duan X, Fu X and Yu C: Synergistic inhibition of endochondral bone formation by silencing Hif $1 \alpha$ and Runx2 in trauma-induced heterotopic ossification. Mol Ther 19: 1426-1432, 2011.

28. Sims NA and Martin TJ: Coupling the activities of bone formation and resorption: A multitude of signals within the basic multicellular unit. Bonekey Rep 3: 481, 2014.

This work is licensed under a Creative Commons Attribution-NonCommercial-NoDerivatives 4.0 International (CC BY-NC-ND 4.0) License. 